University of Nebraska - Lincoln

DigitalCommons@University of Nebraska - Lincoln

Faculty Publications: Department of

Entomology

Entomology, Department of

December 1994

\title{
Characterization of General Esterases from Susceptible and Parathion-Resistant Strains of the Greenbug (Homoptera: Aphididae)
}

\author{
Midori Ono \\ University of Nebraska-Lincoln \\ Jonathan S. Richman \\ University of Nebraska-Lincoln \\ Blair Siegfried \\ University of Nebraska-Lincoln, bsiegfried1@ufl.edu
}

Follow this and additional works at: https://digitalcommons.unl.edu/entomologyfacpub

Part of the Entomology Commons

Ono, Midori; Richman, Jonathan S.; and Siegfried, Blair, "Characterization of General Esterases from Susceptible and Parathion-Resistant Strains of the Greenbug (Homoptera: Aphididae)" (1994). Faculty Publications: Department of Entomology. 58.

https://digitalcommons.unl.edu/entomologyfacpub/58

This Article is brought to you for free and open access by the Entomology, Department of at DigitalCommons@University of Nebraska - Lincoln. It has been accepted for inclusion in Faculty Publications: Department of Entomology by an authorized administrator of DigitalCommons@University of Nebraska - Lincoln. 


\title{
Characterization of General Esterases from Susceptible and Parathion-Resistant Strains of the Greenbug (Homoptera: Aphididae)
}

\author{
MIDORI ONO, JONATHAN S. RICHMAN, AND BLAIR D. SIEGFRIED ${ }^{1}$ \\ Department of Entomology, 202 Plant Industry Building,
} University of Nebraska, Lincoln, NE 68583

\begin{abstract}
J. Econ. Entomol. 87(6): 1430-1436 (1994)
ABSTRACT A susceptible and two parathion-resistant strains of the greenbug, Schizaphis graminum (Rondani), exhibit three different patterns of general esterase isozymes in native polyacrylamide electrophoresis gels. Characterization of general esterase activity using $\alpha$-naphtholic esters as model substrates indicated that the three strains differed in isozyme composition. The type-II strain, which had the highest level of resistance, exhibited the highest levels of general esterase activity under all assay conditions, and the type-I strain had consistently higher levels than the susceptible strain. In all three strains, these esterases were more active toward $\alpha$-naphtholic esters with side chains of six or fewer carbon atoms. $\alpha$-Naphthyl propionate was the optimal substrate for both susceptible and type-I strains, and $\alpha$-naphthyl butyrate for type II. Over $90 \%$ of esterase activity was localized in the cytosolic fraction of type-II greenbugs. In susceptible and type-I greenbugs, the activity was distributed equally between the cytosolic and microsomal fractions. Differences in kinetic properties of the general esterases from the three strains also were evident, further indicating differences in isozyme composition. Although the three strains differed in properties of the general esterase activities, the differences do not provide sufficient discrimination to distinguish reliably among the three strains using single aphid activity measurements.
\end{abstract}

KEY WORDS Schizaphis graminum, resistance, esterase

The GREenBUg, Schizaphis graminum (Rondani), is a serious pest of small grains and sorghum throughout the midwestern United States. Organophosphate insecticides, such as parathion, have been used widely to control greenbugs. However, by the mid-1970s the greenbug's widespread resistance to the systemic organophosphate disulfoton resulted in increased application rates and an eventual rotation to other insecticides (Peters et al. 1975, Teetes et al. 1975). Although resistance in greenbugs resulted in control failures and economic loss, the development of resistant sorghum cultivars circumvented the resistance problem (Peters et al. 1975, Teetes et al. 1975), and the study of insecticide resistance in greenbugs was largely discontinued. Nonetheless, insecticides still are used frequently to control greenbugs, especially since the development of new greenbug biotypes that are capable of overcoming a resistant cultivar's defenses. Recent reports of greenbug-control failures from several areas of the Midwest (Sloderbeck et al. 1991) have resulted in renewed interest in greenbug resistance to insecticides.

1 To whom correspondence should be addressed.
The mechanism of resistance in greenbug strains collected from areas of control failures involves esterase-mediated insecticide detoxification based on the combined results of in vivo and in vitro metabolism studies (Siegfried \& Ono 1993a, b; M.O. \& B.D.S., unpublished data). In many examples of esterase-mediated insecticide resistance, the resistant insects display high levels of nonspecific esterase activity. Homogenates of resistant insects also exhibit one or more intensified esterase bands obtained when subjected to polyacrylamide gel electrophoresis. In resistant greenbugs collected from areas of control failure, enhanced nonspecific esterase activity has been observed with two distinct patterns of enhanced esterase bands (R. Shufran, Department of Entomology, Kansas State University, personal communication). The two resistant strains exhibited 20 - to 30 -fold resistance to parathion (Siegfried \& Ono 1993a, b). Type-I greenbugs produced a single esterase band that was either absent or undetectable in susceptible greenbugs (Fig. 1). Type-II aphids produced multiple, darkly staining esterase bands relative to the susceptible strain, although a single band predominated in this pattern (Fig. 1). A population of greenbugs that produces a combination of 


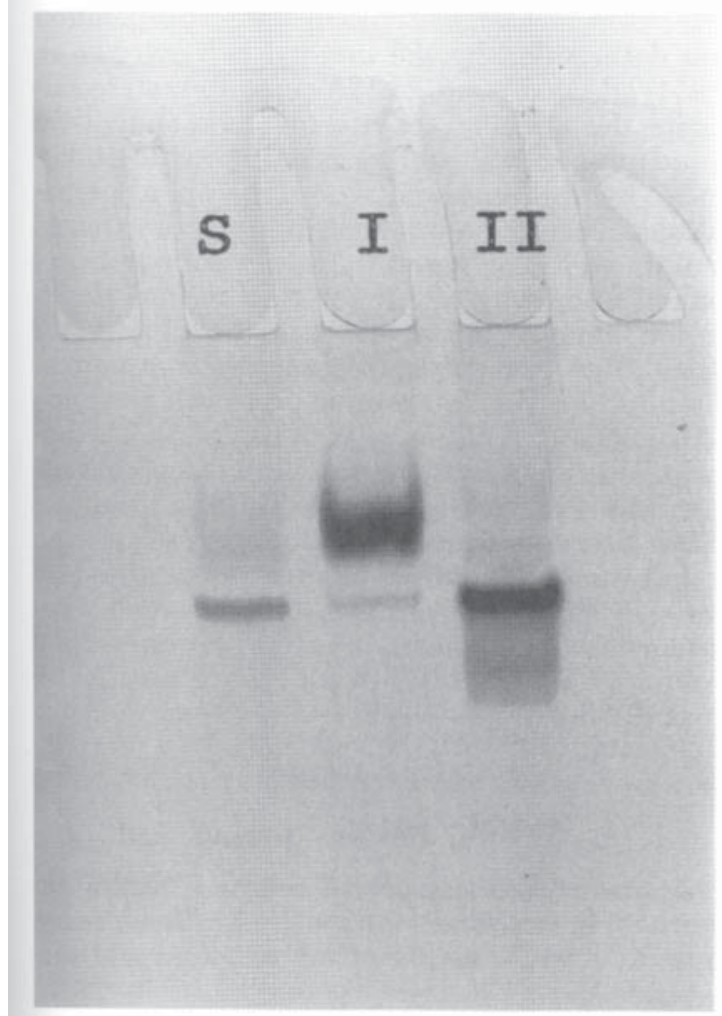

Fig. 1. Native polyacrylamide electrophoresis gel of greenbug esterases. Three patterns represent the susceptible (S), type I (I), and type II (II) strains from left to right when a native gel was stained with $\alpha$-naphthyl acetate and Fast Garnet Red.

the two esterase banding patterns has not been observed.

Because enhanced esterase activity is at least partially responsible for parathion resistance in greenbugs, esterases from susceptible and resistant greenbugs may have different properties that potentially could be used to distinguish between resistant and susceptible insects. Therefore, general esterase activity was characterized to determine differences among greenbugs from susceptible and resistant strains and to optimize conditions for assay. Assays of individual greenbugs using the optimized conditions then were done to evaluate the technique as a possible monitoring tool.

\section{Materials and Methods}

Greenbug Strains. Colonies of the two parathion-resistant greenbug strains were established from field collections from areas of organophosphate-insecticide control failure. A colony from western Kansas, collected by William Black, Kansas State University, was established in Nebraska in January 1990. This strain is referred to as the type-I resistant strain based on the pattern of esterase isozymes observed in polyacrylamide electrophoresis gels. The other resistant strain was collected in Sherman County, TX. A colony provided by Roxanne Shufran, Kansas State University, was established at the University of Nebraska in October 1991. This strain is referred to as type II, based on its esterase banding pattern. The susceptible greenbugs were collected from Lancaster County, Nebraska, in August 1990. All colonies were maintained on sorghum, Sorghum bicolor (L.) Moench, seedlings (Funks G-522A) at $26^{\circ} \mathrm{C}$ and a photoperiod of $16: 8(\mathrm{~L}: \mathrm{D}) \mathrm{h}$.

Chemicals. All $\alpha$-naphtholic esters and biochemical reagents were purchased from Sigma (St. Louis, MO). Electrophoresis reagents were purchased from Bio-Rad (Hercules, CA). All other chemicals and solvents were of reagent grade or better.

Enzyme Preparation and Assay. Resistant and susceptible greenbugs were homogenized in $0.02 M$ sodium phosphate buffer ( $\mathrm{pH} 7.0$ ) containing $1 \%$ triton-X 100 with a Teflon glass homogenizer (Potter-Elvehjem). The homogenate was centrifuged at $10,000 \times g$ for $20 \mathrm{~min}$ in a microcentrifuge, and protein concentration of the supernatant was determined by the method of Bradford (1976). The concentrations were adjusted to $0.5 \mathrm{mg} / \mathrm{ml}$ for the susceptible and type-I strains, and to $0.2 \mathrm{mg} / \mathrm{ml}$ for the type-II strain. Activity of general esterases was assayed by colorimetric measurement of $\alpha$-naphthol formation in each reaction mixture. Absorbance was recorded at $605 \mathrm{~nm}$ (van Asperen 1962) in a spectrophotometer (Beckman DU-65, Palo Alto, CA). In general, the assay mixture contained $0.02 M$ sodium phosphate buffer ( $\mathrm{pH} 7.0), 10 \mu \mathrm{l}$ of enzyme preparation, and $0.25 \mathrm{mM}$ of substrate. Control incubations without enzyme were done with samples to estimate nonspecific breakdown of the substrate. The assay was initiated by the addition of substrate, and the mixture was incubated in a shaking waterbath at $30^{\circ} \mathrm{C}$ for $15 \mathrm{~min}$. After incubation, the reaction was stopped by addition of $166 \mu \mathrm{l}$ of $0.3 \%$ diazo blue B (o-dianisidine, tetrazotized) in $3.5 \%$ sodium lauryl sulfate. Formation of product was determined from a standard curve of $\alpha$-naphthol.

To measure substrate specificity, eight $\alpha$ naphtholic esters differing in chain length of the carbon side chain were used as follows: $\alpha$ naphthyl acetate (C-2), propionate (C-3), butyrate $(\mathrm{C}-4)$, valerate $(\mathrm{C}-5)$, caproate $(\mathrm{C}-6)$, caprylate $(\mathrm{C}-8)$, nonanoate $(\mathrm{C}-9)$, and caprate $(\mathrm{C}-10)$. Temperature effects on esterase activity were determined by testing with incubations from 15 to $60^{\circ} \mathrm{C}$ in $5^{\circ} \mathrm{C}$ increments. Sodium phosphate buffers from $\mathrm{pH} 6.4$ to 8.0 were tested to examine $\mathrm{pH}$ effects on esterase activity. Kinetic properties were studied by testing a series of concentrations of $\alpha$-naphthyl butyrate, establishing Lineweaver- 
Burk plots (Lineweaver \& Burk 1934), and estimating $V_{\max }$ and $K_{M}$ values for each strain.

Subcellular Distribution. Approximately $0.2 \mathrm{~g}$ of greenbugs was homogenized in $1 \mathrm{ml}$ of $0.02 \mathrm{M}$ sodium phosphate buffer ( $\mathrm{pH} 7.0)$ as described, and protein concentration and esterase activity in the crude homogenate were determined. The homogenate was centrifuged at $10,000 \times \mathrm{g}$ for $20 \mathrm{~min}$. The resulting pellet was resuspended in a separate $500-\mu \mathrm{l}$ aliquot of buffer. The supernatant was centrifuged in an ultracentrifuge (Beckman TL-100) at $100,000 \times g$ for $\mathbf{l ~ h}$. The resulting microsomal pellet was resuspended in $1 \mathrm{ml}$ of buffer, and the supernatant was saved as the cytosolic fraction. The resulting three fractions and the crude homogenate from each strain were tested for protein concentration and esterase activity.

Gel Electrophoresis. Continuous native polyacrylamide gel electrophoresis was performed in a vertical unit (Mini-Protean II, Bio-Rad, Palo Alto, CA) by using a $7.5 \%$ acrylamide gel with a continuous Tris/glycine buffer system $(50 \mathrm{mM}$, $\mathrm{pH}$ 8.3). Samples were diluted $1: 1$ with $50 \mathrm{mM}$ Tris/glycine buffer (pH 8.3) with $20 \%$ sucrose (wt:vol). Individual wells were loaded with equal amounts of protein, and $0.1 \%$ Bromophenol Blue in $10 \%$ sucrose was used as marker in each gel. Gels were run at $200 \mathrm{~V}$ constant voltage for $45 \mathrm{~min}$. The gels were stained for esterase activity in $100 \mathrm{ml} 0.2 \mathrm{M}$ sodium phosphate buffer (pH 7.0), 2\% (by volume) $30 \mathrm{mM} \alpha$-naphthyl acetate dissolved in acetone, and $0.04 \mathrm{~g}$ Fast Garnet GBC Salt (Siegfried \& Scott 1992).

Single Aphid Assays. Individual greenbugs were placed into wells of a 96-well flat-bottom ELISA plate, (Corning, Corning, NY) containing $130 \mu \mathrm{l}$ of cold $0.02 \mathrm{M}$ sodium phosphate buffer ( $\mathrm{pH} 7.0$ ) containing $1 \%$ Triton X-100. Aphids were homogenized by circular and vertical movements of a 96-spoke inoculating manifold (model no. MC96, Dan-Kar, Reading, MA) for 3 min per plate. The homogenate $(25 \mu \mathrm{l})$ from each homogenizing well then was transferred using an eight-channel pipettor into the corresponding well on a separate ELISA plate. Nonspecific esterase activity of the individual aphid homogenates then was tested, as described by van Asperen (1962), by measuring the production of $\alpha$-naphthol from $\alpha$-naphthyl butyrate. The assay mixture consisted of $25 \mathrm{mM} \alpha$-naphthyl butyrate in $0.02 \mathrm{M}$ sodium phosphate ( $\mathrm{pH} 7.0$ ). The plates were incubated at $30^{\circ} \mathrm{C}$ for $15 \mathrm{~min}$. The reaction then was stopped, and color developed by the addition of $33 \mu \mathrm{l} 0.3 \%$ diazo blue B in $3.5 \%$ sodium lauryl sulfate.

The absorbance at $630 \mathrm{~nm}$ was read after 15 min against an enzyme blank in a microplate reader (Bio-Kinetics EL312e, Bio-Tek Instruments, Winooski, VT). The concentration of hydrolyzed substrate was determined from a standard curve of $\alpha$-naphthol. The protein con- centration of each individual aphid preparation was determined by the method of Lowry et al. (1951) adapted to an ELISA-plate format, to calculate the specific activity for each individual aphid preparation and to avoid activities influenced by differences in size of the aphid preparations. The frequency distributions of esterase activity were compared by fitting data to an expected frequency of a theoretical normal distribution around the same mean (Sokal \& Rholf 1969). Significance of difference from a normal distribution was determined from the ShapiroWilk statistic, $W$ (Shäpiro \& Wilk 1965). The appropriate summary statistics were calculated using SAS PROC UNIVARIATE (SAS Institute 1988). The significance of differences in esterase activity among the three strains was analyzed by one-way analysis of variance, and differences between treatment means were determined by a protected least significant difference test (Neter et al. 1985).

\section{Results}

Optimal Conditions for General Esterase Activity. The results of the experiments to optimize general esterase activity from resistant and susceptible greenbugs are reported in Fig. 2A-C. Esterase activity toward eight $\alpha$-naphtholic esters varying in length of the carbon side chain is shown in Fig. 2A. The three strains generally exhibited a similar pattern of activity across the range of substrates tested. However, the susceptible and type-I strains exhibited maximum activity toward $\alpha$-naphthyl propionate (C-3), whereas the type-II strain exhibited maximum activity toward $\alpha$-naphthyl butyrate (C-4). Activity toward $\alpha$-naphtholic esters with side chains of more than six carbon atoms declined considerably in all strains. Because of the large differences in activity between the susceptible and two resistant strains, $\alpha$-naphthyl butyrate (C-4) was used as the substrate in further experiments. The overall trend of esterase activity toward the model substrates was the same for all three strains, and the order of levels of activity were type II > type I > susceptible for all substrates tested.

Esterase activity toward $\alpha$-naphthyl butyrate at different incubation temperatures showed a similar trend for the susceptible and type-I resistant strains (Fig. 2B). Type-II greenbugs exhibited similar levels of activity between 30 and $50^{\circ} \mathrm{C}$, whereas the susceptible and type-I strains exhibited a more gradual increase in activity up to $45^{\circ} \mathrm{C}$. At incubation temperatures $>50^{\circ} \mathrm{C}$, activity was reduced sharply in all strains. Type-II esterase maintained several-fold higher levels of activity at all temperatures. Although greenbug esterases maintained high levels of activity at $\leq 50^{\circ} \mathrm{C}$, incubation at $30^{\circ} \mathrm{C}$ was used in all other 

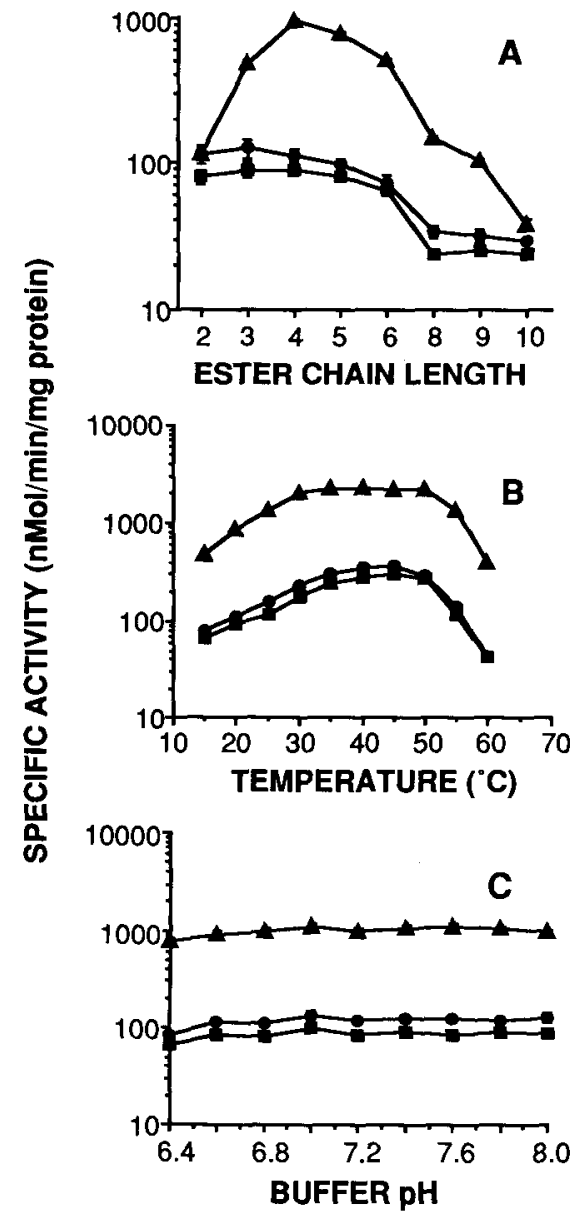

\section{SUSCEPTIBLE}

TYPE 1

A TYPE II

Fig. 2. Optimal conditions for assay of greenbug general esterases as follows: (A) Esterase activity ( $\log _{10}$ scale) toward eight $\alpha$-naphtholic esters differing in carbon side chain length (2, acetate; 3 , propionate; 4 , butyrate; 5 , valerate; 6 , caproate; 8 , caprylate; 9 , nonanoate; 10 , caprate); (B) esterase activity $\left(\log _{10}\right.$ scale) as a function of temperature; (C) esterase activity as a function of $\mathrm{pH}$. Each point represents the means of at least nine determinations.

experiments because it exhibited optimum differences.

Esterase activity was not influenced greatly by buffer $\mathrm{pH}$ between 6.0 and 8.0 (Fig. 2C). Type II maintained about 10-fold higher levels of activity throughout the tested range, and type I exhibited consistently higher levels of activity than the susceptible strain. The optimum $\mathrm{pH}$ for all three strains was 7.0, and, therefore, sodium phosphate buffer at $\mathrm{pH} 7.0$ was used for all other experiments.

Kinetics. Kinetic analysis of general esterase activity toward $\alpha$-naphthyl butyrate is shown in Fig. 3. $V_{\max }$ and $K_{M}$ were calculated from the

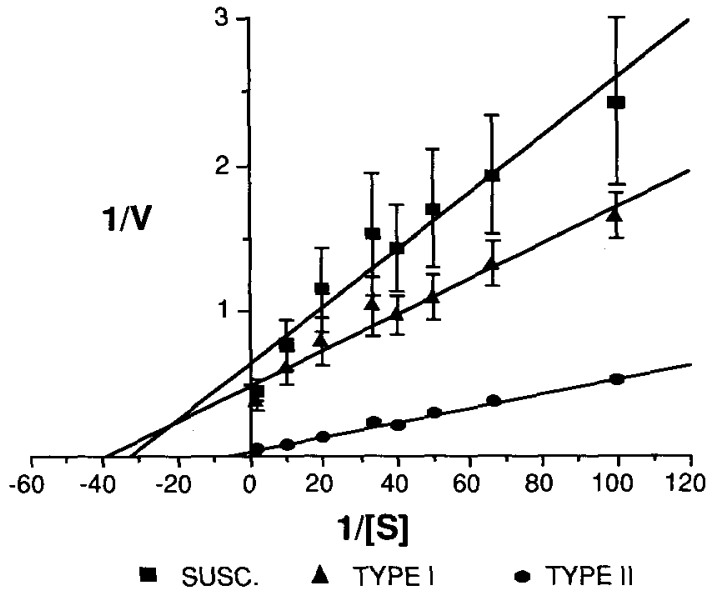

Fig. 3. Lineweaver-Burk plots of susceptible, type I, and type II general esterase activity. The units for reaction velocities (V) and substrate concentrations ([S]) are $\mathrm{nMol} / \mathrm{min}$ and $\mathrm{mM}$, respectively. Each point represents the mean of at least nine determinations.

Lineweaver-Burk double reciprocal plots for each strain under optimal conditions. $V_{\max }$ and $K_{M}$ values were $1.31 \mathrm{nmol} / \mathrm{min}$ and $2.31 \times 10^{-5} \mathrm{M}$ for the susceptible, $1.794 \mathrm{nmol} / \mathrm{min}$ and $2.11 \times$ $10^{-5} M$ for type $\mathrm{I}$, and $27.683 \mathrm{nmol} / \mathrm{min}$ and $1.378 \times 10^{-4} M$ for type II. Although the experiments were done with preparations containing multiple esterases, these results indicate differences among the three strains and are indicative of differences in isozyme composition.

Subcellular Distribution. Subcellular distribution of esterase activity is summarized in Table 1. Esterase specific activity from type-II greenbugs was higher than those from type I and the susceptible strain, and esterase specific activity from type I was higher than that from the susceptible strain in all fractions. Similar patterns of distribution were obtained from the susceptible and type-I strains, in which esterase activity was distributed almost equally among fractions. However, the type-II strain exhibited a different pattern, in which the cytosolic fraction contained $>90 \%$ of the total activity.

Single Aphid Bioassays. The results of tests to discriminate between resistant and susceptible greenbugs using general esterase activity measurements adapted for single aphid assays are shown in Fig. 4. Mean activities for the three strains (Table 2) were significantly different among the three strains, although the distribution curves clearly show considerable overlapping in esterase activities. Such overlap is especially true of the type I and susceptible strains where at least $50 \%$ overlap of the two distributions was observed. The statistics of locations (mean and median) and dispersion (SD, skewness, and kurtosis) that describe the frequency distributions for the three strains are summa- 
Table 1. Subcellular distribution of general esterase from resistant and susceptible greenbugs

\begin{tabular}{|c|c|c|c|}
\hline Strain & Fraction & $\begin{array}{l}\text { Specific activity } \\
(\mathrm{nMol} / \mathrm{min} \text { per } \mathrm{mg} \text { protein })^{a}\end{array}$ & $\%$ Total activity ${ }^{b}$ \\
\hline \multirow[t]{5}{*}{ Susceptible } & Crude homogenate & $227.14 \pm 33.03$ & 100 \\
\hline & $10,000 \times g$ pellet & $162.54 \pm 11.56$ & 30.0 \\
\hline & $100,000 \times g$ supernatant & $151.57 \pm 12.09$ & 32.9 \\
\hline & $100,000 \times g$ pellet & $235.87 \pm 20.56$ & 24.2 \\
\hline & $\%$ recovery & & 87.1 \\
\hline \multirow[t]{5}{*}{ Type I } & Crude homogenate & $213.03 \pm 10.90$ & 100 \\
\hline & $10,000 \times g$ pellet & $199.27 \pm 8.71$ & 29.5 \\
\hline & $100,000 \times g$ supernatant & $166.02 \pm 3.14$ & 31.7 \\
\hline & $100,000 \times g$ pellet & $274.32 \pm 20.16$ & 31.7 \\
\hline & $\%$ recovery & & 88.0 \\
\hline \multirow[t]{5}{*}{ Type II } & Crude homogenate & $5,331.8 \pm 214.15$ & 100 \\
\hline & $10,000 \times g$ pellet & $888.65 \pm 112.38$ & 29.1 \\
\hline & $100,000 \times g$ supernatant & $2,201.5 \pm 369.08$ & 92.7 \\
\hline & $100,000 \times g$ pellet & $516.14 \pm 71.03$ & 11.8 \\
\hline & $\%$ recovery & & 133.6 \\
\hline
\end{tabular}

${ }^{a}$ Each value for the susceptible strain represents the mean of 18 determinations and for types I and II, the mean of nine determinations.

${ }^{b}$ Each value was based on three sets of data for the resistant strains and six for the susceptible strain.

rized in Table 2. Each distribution differed significantly from a normal distribution $(P<0.05)$. Both the susceptible and type-I strains exhibited positive kurtosis (higher frequency near the mean and tails of the distribution) and positive skewness (asymmetry to the right). The type-II strain exhibited negative kurtosis, indicating a lower frequency near the mean and tails of the distribution.

\section{Discussion}

Although the three strains displayed similar trends in esterase activity toward different model substrates and under different incubation conditions, the type-I strain consistently displayed two- to three-fold higher levels of activity than

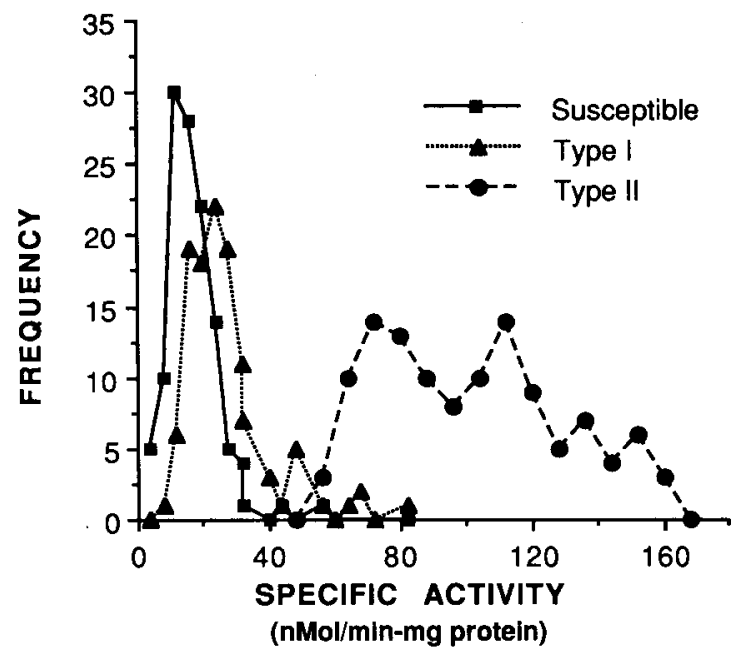

Fig. 4. Frequency distribution of greenbug general esterase activity from single aphid homogenates. The sample size for each of the tested populations was 120 apterous adults. the susceptible strain, and the type-II strain exhibited $>10$-fold higher activity levels. In addition, differences in optimal assay conditions, kinetic properties, and electrophoretic mobility of esterase isozymes strongly suggest that these strains differ quantitatively in isozyme composition and that at least two different esterases confer resistance to organophosphate insecticides.

The activity profile of the three strains toward $\alpha$-naphtholic esters indicated that $\alpha$-naphtholic esters with side chains of six or fewer carbon atoms were better model substrates for greenbug esterases. Similar observations have been made in Myzus persicae (Sulzer), Myzus nicotianae Blackman (Abdel-Aal et al. 1990), and Blattella germanica (L.) (Siegfried \& Scott 1992), in which the optimum model substrate was either $\alpha$ naphthyl propionate or $\alpha$-naphthyl butyrate. Greenbug esterases were active over a wide range of temperature and are fairly stable at

Table 2. Statistical parameters calculated from fitting the observed frequency distributions of esterase activity in individual greenbugs to the expected frequencies in theoretical normal distributions with the same means

\begin{tabular}{|c|c|c|c|}
\hline \multirow{2}{*}{ Parameter } & \multicolumn{3}{|c|}{$\begin{array}{c}\text { Specific activity } \\
\text { (nMole/min per mg protein) }\end{array}$} \\
\hline & Susceptible & Type I & Type II \\
\hline $\operatorname{Mean}^{a}$ & $17.54 \mathrm{a}$ & $28.33 b$ & $102.48 \mathrm{c}$ \\
\hline SD & 7.75 & 15.63 & 30.34 \\
\hline Median & 16.42 & 24.71 & 101.15 \\
\hline Skewness ${ }^{b}$ & 1.81 & 2.64 & 0.45 \\
\hline Kurtosis $^{c}$ & 6.33 & 9.86 & -0.311 \\
\hline
\end{tabular}

\footnotetext{
${ }^{a}$ Means followed by the same letter within a row are not significantly different $(P>0.05$; protected least significance difference [Neter et al. 1985]).

${ }^{b}$ Negative values of skewness indicate asymmetry to the left of the mean, whereas positive values indicate asymmetry to the right

${ }^{c}$ Negative values of kurtosis imply lower frequency, whereas positive values imply higher frequency near the mean and tails of the distribution.
} 
$\leq 50^{\circ} \mathrm{C}$. The esterases were active between $\mathrm{pH}$ 6.0 and 8.0 , although levels of activity were slightly higher under neutral and basic conditions.

Differences in isozyme composition may account for differences in general esterase activity among strains because the measured activity represents the combined activity of several isozymes, each with its own set of optimal assay conditions. The kinetic properties of these esterases apparently differ among the strains. These results must be interpreted with caution, however, because our study was done with crude homogenates that contained several different esterase isozymes, as based on electrophoresis banding patterns. In addition, these results may not relate directly to differences in resistance levels because kinetic properties could be much different for insecticide substrates. Nevertheless, $V_{\max }$ and $K_{M}$ values from the three strains differed sufficiently to support our hypothesis that differences in isozyme composition produced the different electrophoretic band patterns. These electrophoretic band patterns suggest that certain isozymes are enhanced in the resistant strains and that the isozyme enhanced in type II displayed greater activity toward $\alpha$-naphthyl butyrate than the intensified isozyme in type $I$.

The three strains also differed in the subcellular distribution of esterase activity. Whereas the cytosolic fraction contained $>90 \%$ of the total activity in type II, almost equal esterase activities were detected in all fractions for the susceptible and type-I strains. Levels of activity for the three strains were consistent with previous experiments in that type II always exhibited as much as 10-fold more activity than susceptible greenbugs and activity of type I was two- to threefold higher than that of the susceptible strain. The order of activity levels agreed with the order of resistance levels (i.e., type II $>$ type I > susceptible), although the three strains exhibited greater differences in resistance than in esterase activities, especially for the type-I strain. This discrepancy may be related to substrates, because activity toward model substrates may not reflect esterase activity toward insecticide substrates.

The difference between type-I and type-II strains, especially in kinetic properties, suggests that these two strains possess different esterase isozymes but use similar processes to achieve resistance. Although the level of resistance is associated strongly with significantly higher general esterase activity in the two resistant strains, we could not discriminate completely between resistant and susceptible strains based on general esterase activities from individual aphids. Just as there is overlap in dose-mortality regressions among the three populations (Siegfried \& Ono $1993 \mathrm{a}, \mathrm{b}$ ), the overlap of esterase activity precludes use of this technique for monitoring resistance frequencies among field populations of greenbugs. However, differences in isozyme composition noted for the three strains may be diagnostic either by electrophoretic separation of individual isozymes or through immunological techniques that completely discriminate between resistant and susceptible individuals. Such specificity in identification would be ideally suited for resistance monitoring of field populations. These monitoring techniques would provide a means to assess the genetic potential for resistance to occur and allow resistance profiles to be developed before choosing a pesticide so that ineffective and wasted applications could be avoided (ffrench-Constant \& Roush 1990).

\section{Acknowledgments}

We thank W. Black (Colorado State University) and R. Shufran (Kansas State University) for supplying the resistant greenbugs. S. Kamble, D. Stanley-Samuelson, and S. Prabhakaran (University of Nebraska) provided critical reviews of an early draft of the manuscript. J. Jensen, T. Carlstrom, and A. Cunningham provided valuable technical assistance throughout the project. Funding for this work was provided through North Central Region Pesticide Impact Assessment Program (project no. 541-2) and the University of Nebraska Water Center. This is journal series paper 10546, Nebraska Agricultural Research Division, and contribution no. 846 of the Department of Entomology, University of Nebraska.

\section{References Cited}

Abdel-Aal, Y.A.I., M. A. Wolff, R. M. Roe \& E. P. Lampert. 1990. Aphid carboxylesterases: biochemical aspects and importance in the diagnosis of insecticide resistance. Pestic. Biochem. Physiol. 38: 255-266.

Bradford, M. M. 1976. A rapid and sensitive method for the quantitation of microgram quantities of protein utilizing the principle of protein-dye binding. Anal. Biochem. 72: 248-254.

french-Constant, R. H. \& R. T. Roush. 1990. Resistance detection and documentation: the relative roles of pesticidal and biochemical assays, pp. 4-38. In R. T. Roush \& B. E. Tabashnik [eds.], Pesticide resistance in arthropods. Chapman \& Hall, New York.

Lineweaver, H. \& D. Burk. 1934. The determination of enzyme dissociation constants. J. Am. Chem. Soc. 56: 658-666.

Lowry, O. H., N. J. Rosebrough, A. L. Farr \& R. J. Randall. 1951. Protein measurement with folin phenol reagent. J. Biol. Chem. 193: 265-275.

Neter, J., W. Wasserman \& M. H. Kutner. 1985. Applied linear statistical models. Richard D. Irwin, Homewood, IL.

Peters, D. C., E. A. Woods, Jr., \& K. J. Starks. 1975. Insecticide resistance in selections of the greenbug. J. Econ. Entomol. 68: 339-340.

SAS Institute. 1988. SAS user's guide: statistics. SAS Institute, Cary, NC.

Shapiro, S. S. \& M. B. Wilk. 1965. An analysis of variance test for normality. Biometrika 52: 591-611. 
Siegfried, B. D. \& M. Ono. 1993a. Mechanisms of parathion resistance in the greenbug, Schizaphis graminum (Rondani). Pestic. Biochem. Physiol. 45: $24-33$.

1993b. Parathion toxicokinetics in resistant and susceptible strains of the greenbug (Homoptera: Aphididae). J. Econ. Entomol. 86: 1317-1323.

Siegfried, B. D. \& J. G. Scott. 1992. Biochemical characterization of hydrolytic and oxidative enzymes in insecticide resistant and susceptible strains of the German cockroach (Dictyoptera: Blattellidae). J. Econ. Entomol. 85: 1092-1098.

Sloderbeck, P. E., M. A. Chowdhury, L. J. DePew \& L. L. Buschman. 1991. Greenbug (Homoptera:
Aphididae) resistance to parathion and chlorpyrifosmethyl. J. Kans. Entomol. Soc. 64: 1-4.

Sokal, R. R. \& F. J. Rholf. 1969. Biometry. Freeman, San Francisco.

Teetes, G. L., C. A. Schaefer, J. R. Gipson, R. C. McIntyre \& E. E. Latham. 1975. Greenbug resistance to organophosphorus insecticides on the Texas High Plains. J. Econ. Entomol. 63: 214-216.

van Asperen, K. 1962. A study of housefly esterases by means of a sensitive colorimetric method. J. Insect Physiol 8: 401-416.

Received for publicution 13 December 1993; accepted 23 June 1994. 